\title{
The Microglial Metamorphosis in Three-dimensions in Virus Limbic Encephalitis: An Unbiased Pictorial Representation Based on Stereological Sampling Approach of Surveillant and Reactive Microglia
}

Leonardo Sávio da Silva Creão ${ }^{1,2}$, João Bento Torres Neto ${ }^{2,3}$, Camila Mendes de Lima ${ }^{2}$, Renata Rodrigues dos Reis 2, Aline Andrade de Sousa ${ }^{2}$, Zaire Alves dos Santos ${ }^{2}$, José Antonio Picanço Diniz ${ }^{4}$, Daniel Guerreiro Diniz ${ }^{1,2,4^{*}}$, Cristovam Wanderley Picanço Diniz ${ }^{1,2}$

1 Núcleo de Pesquisas em Oncologia, Programa de Pós-Graduação em Oncologia e Ciências Médicas, Hospital Universitário João de Barros Barreto, Universidade Federal do Pará, Belém, Pará, Brasil.

2 Laboratório de Investigações em Neurodegeneração e Infecção, Hospital Universitário João de Barros Barreto, Instituto de Ciências Biológicas, Universidade Federal do Pará, Belém, Pará, Brasil.

3 Faculdade de Fisioterapia e Terapia Ocupacional, Universidade Federal do Pará, Belém, Pará, Brasil.

4 Laboratório de Microscopia Eletrônica, Instituto Evandro Chagas, Belém, Pará, Brasil.

* Dr. Daniel Guerreiro Diniz, Address: Hospital Universitário João de Barros Barreto, Laboratório de Investigações em Neurodegeneração e Infecção, Rua dos Mundurucus 4487, Guamá, CEP: 66.073-005, Belém, Pará, Brasil. E-mail: danielguerreirodiniz@gmail.com

\begin{abstract}
All neurological diseases have their pathological progress influenced by microglial cells, which react to insults with multiple morphofunctional phenotypes. However, the complete morphological spectrum of the reactive microglia, revealed by the three-dimensional microscopic reconstruction, has not been explored in detail in virus limbic encephalitis. Here, we used anatomical series of brain sections from a previous study using Piry arbovirus encephalitis, expanding the original investigation to CA1/CA2. The morphological response of the homeostatic and reactive microglia was investigated 8 days after infection. The hierarchical cluster and linear discriminant function analysis of multimodal morphometric features allowed to distinguish between the microglial morphology of infected individuals and controls. In order to represent more broadly the morphological spectrum of the microglia of each cluster, representative cells of the homeostatic and reactive microglia were chosen, using the sum of the distances of each cell in relation to all the others. Overall, the multivariate statistical analysis showed that the reactive microglia of infected animals have more complex trees and thicker branches, that cover a larger volume of tissue than the microglia of control animals. With this approach a more reliable representation of the microglia dispersion in the Euclidean space, would be closer to the spectrum of morphotypes of the control and infected groups, and help to avoid hiding the morphological kaleidoscope of surveillant and reactive microglia. As form precedes function in nature, our findings are a good starting point for future research with integrative approaches to microglia form and function.
\end{abstract}

Keywords: Viral encephalitis; Microglia; Quantitative neuropathology; Piry virus; Albino Swiss mice

\section{Introduction}

Viral encephalitis represents $20-50 \%$ of the total number of encephalitis in the United States of America, and among the known viruses, the herpes simplex virus (HSV) is responsible for 50 to $75 \%$ of identified human encephalitis cases, the remaining encephalitis being associated with varicella-zoster virus (VZV), enterovirus and arbovirus [1]. During the past few decades, endemic arboviruses in Europe have expanded their geographical 
distribution and caused an increasing number of outbreaks in humans [2]. Most arboviruses originally found in tropical regions, such as Africa and South America, or in some regions of Asia, are now widely dispersed causing disease worldwide, including encephalitis. Several reasons contributed to the dispersion of arboviruses in new geographic areas, including global warming, increased urbanization, population growth in tropical regions, faster transport and the rapid spread of arthropod vectors [3]. However, many of the mechanisms underlying the inflammatory response associated with virus encephalitis remain unknown $[4,5]$, and those produced by arboviruses with important neurocognitive impairments do not escape this rule [6]. Although microglia constitute approximately $7 \%$ of non-neuronal cells in different brain structures, as well as in the entire brain of many mammalian species [7], their diverse of reactive phenotypes and contribution to maintaining CNS homeostasis is remarkable [8]. For this reason, the experimental studies dedicated to the microglial response of the adult host to encephalitis associated with arboviruses, such as the one we have undertaken in the present work, remain essential to understanding its neuropathogenesis.

The morphological features of microglia are found to be significantly different in the central nervous system (CNS), with great variation in its ramifications, cell size and gene expressions between the species studied until then [9]. Although the number of microglial homeostatic functions in the healthy CNS remains poorly defined and subject to many speculations [10], it is already known that microglial processes sweep the surrounding environment, monitoring the synapses' functional state, regulate neuronal activity in all stages of development and adult life, and participate in the remodeling and maturation of synaptic circuits through their contacts with pre- and post-synaptic membranes [1113]; for a recent review, see [14].

In addition to the homeostatic microglial profile, there are multiple reactive microglial states, with their own physiological contributions, regulated by purinergic mechanisms, which come into play from the discrimination of discrete changes in the brain parenchyma, both in physiological and pathological conditions [15]. The motility of microglia includes constant extension and retraction of its processes to examine the brain, and directing processes to sites with tissue damage, which are controlled by P2Y12 activation and membrane potential [16]. The microglia also exhibit nanoscale surveillance with adaptation of filopodia and increased local concentration of cAMP, and this change in intracellular levels of cAMP controls the polarity of microglial responses and changes the scale of surveillance work [17].

Recently, the morphology of the microglia was directly correlated to gene expression in the central nervous system of mice using three-dimensional microscopic reconstruction and transcriptomic analysis in the same individuals and it was demonstrated that the total area and volume of the immunolabeled microglial processes for IBA1 and P2Y12 in CA3 of mice submitted to LPS, showed differential significant correlation with selective gene expression in males and females [18]. Different classes of transcription factors interact to select and activate regulatory elements that control microglia responses to a variety of signals [19]. For example, microglia-specific disruption of Irf8 significantly reduced microglia ramification and surface area and altered expression of several cell surface markers, changing microglia phenotype to reactive profile [20].

Thus, it is widely accepted that the function of microglial cells and their forms are closely related and because form precedes the function [21,22] it is a good starting point to analyze morphological changes under altered homeostatic conditions to unravel microglia morphotypes facing an arbovirus encephalitis.

\section{Experimental Procedures}

In this work, 10 adult female Swiss albino mice with 2 months of age were used, originating from the colony of the Animal House of the Evandro Chagas-Pará Institute, and manipulated according to the "Principles of Laboratory Animal Care" of the National Health Institute (NIH - USA) and of the National Committee for Animal Experimentation 
(CONCEA - Brazil). The use of these animals was approved in 2005 by the Research Ethics Committee with Experimental Animals (CEPAE-UFPA) registered under Protocol number 1701/2005. The present investigation was carried out in compliance with relevant institutional biosafety and biosecurity international protocols adopted by Evandro Chagas Institute.

The adult animals used in this work were the subject of previous investigation [23] and in this work only the anatomical series of brain sections from infected animals and controls sacrificed eight days after intranasal infection with the Piry virus was used. To ensure the clarity of the text, the methodology is briefly presented, but its detailed description can be obtained from previous related publications [23].

\section{Animals and infection}

Ten adult female albino Swiss mice (Mus musculus) at 12 weeks of age were obtained from the animal house of the Evandro Chagas Institute (IEC) and accommodated in standard laboratory cages with five animals in each and kept in a controlled temperature environment $\left(22^{\circ} \mathrm{C}\right)$, with twelve-hour cycles of lighting and interruption, starting at seven in the morning.

For intranasal inoculation, Piry virus infected and non-infected brain homogenates were used. The brain homogenates containing the viruses were obtained from neonatal mice previously infected with the pathogen, provided by the Arbovirology and Hemorrhagic Fever Department following the protocol by [24]. Each brain (0.2g) was macerated in $1.8 \mathrm{ml}$ of $0.1 \mathrm{M}$ phosphate buffer $\mathrm{pH} 7.2-7.4$ (PBS) containing penicillin $(100 \mathrm{U} / \mathrm{ml})$ and streptomycin $(100 \mu \mathrm{g} / \mathrm{ml})$. Soon after the mixture was centrifuged at $10,000 \mathrm{G}$ for 15 minutes at $4^{\circ} \mathrm{C}$. The suspension produced was aliquoted in $0.5 \mathrm{ml}$ tubes and kept at $-70^{\circ} \mathrm{C}$ until use.

Viral titration was performed by intra-cerebral inoculation of $0.2 \mathrm{ml}$ of viral suspension in different dilutions on a multiple scale of 10 in PBS. The median lethal dose (LD50) was calculated by the method of Reed and Muench [25]. The initial LD50/20 $\mu$ l was 8.0 Log10. The viral concentration chosen in this work at each moment was based on the need to obtain a non-lethal dose for the entire colony and that was capable of producing chronic non-fatal encephalitis. $20 \mu \mathrm{l}$ of viral suspension in $0.1 \mathrm{M}$ Phosphate Buffer (PB) solution, $\mathrm{pH} 7.2-7.4$ containing penicillin $(100 \mathrm{U} / \mathrm{ml})$ and streptomycin $(100 \mathrm{mg} / \mathrm{ml})$ were administered intranasally.

The effective dose for each group of experiments varied according to the presence of evident clinical signs and the occurrence of deaths in a proportion less than $50 \%$. A control group consisted of 5 animals that received $20 \mu \mathrm{l}$ of uninfected neonate mouse brain homogenate.

\section{Perfusion and microtomy}

The mice were anesthetized with Avertin, $0.15 \mathrm{ml} / 5 \mathrm{~g}$ of body weight [26], intraperitoneally and perfused intracardially with heparinized saline and $4 \%$ paraformaldehyde in $0.1 \mathrm{M}$ phosphate buffer, $\mathrm{pH} 7.2$ - 7.4. After craniotomy, the brains were kept in $2 \%$ paraformaldehyde for 24 hours and then sectioned in the parasagittal plane at a thickness of $70 \mu \mathrm{m}$ in a vibratome (MICROM, model HM 650V). Anatomical series of sections (1/4) obtained from each brain were divided into four samples equally representative of the whole brain for further processing by immunohistochemistry.

For three-dimensional reconstructions, microglia from control and infected animals were immunolabeled using the anti-IBA-1 antibody ("Ionized calcium binding adapter molecule 1"). IBA-1 is an adapter molecule that binds to calcium in macrophages/microglia, being specifically expressed in these cells, and regulated upwards during microglia activation $[27,28]$. Detailed protocol for immunostaining was previously published elsewhere. Immunoreacted sections were mounted on gelatinized slides, dried at room temperature and subsequently dehydrated in alcohol in various concentrations $(70,80,90$ and $100 \%$ ), diaphanized in xylol and covered with a coverslip using Entellan ${ }^{\circledR}$ (Merck). 
Morphometry based on three-dimensional reconstruction

In sections stained by immunohistochemistry for IBA-1 (microglia) and counterstained by Nissl, the limits of CA1/CA2 were made according to the cytoarchitecture of the parasagittal atlas of Nissl stained sections [29], taking into account the size and degree of packaging of the cells as well as the lamination.

For the three-dimensional reconstruction of the microglia, we used the optical microscope (Eclipse 80i, Nikon) with motorized stage and analog-digital converters (MAC6000 System, Ludl Electronic Products, Hawthorne, NY, USA) to digitally store information related to spatial coordinates $(X, Y, Z)$ of each point of the reconstruction. This system is coupled to a microprocessor that controls the movements of the motorized stage with the aid of a dedicated software (Neurolucida, Microbrightfield, Williston, VT, USA). In order to avoid ambiguities in the identification of objects of interest and to ensure greater precision in reconstructions, the 4.0x objective was replaced by another PLANFLUOR, 100X (NA 1.3; DF $=0.2 \mu \mathrm{m}$; Nikon, Japan) used for three-dimensional reconstructions. Only microglia showing complete branches were used for reconstruction. To ensure that all regions were equally likely to contribute to the sample, we adopted a random and systematic stereological approach to select microglia [30], from a series of sections, containing CA1/CA2. We generated squared probes $(50 \times 50 \mu \mathrm{m})$ over a grid sample $(200 \times 200 \mu \mathrm{m})$ placed over the area of CA1/CA2, the area of interest. From each squared probe we select single microglia for 3D reconstruction removing the sample bias. We applied a correction for retraction induced by histological processing in the morphometric data limited to Zaxis, in a linear way, for all experimental groups, where $75 \%$ of shrinkage was assumed to occur as previously suggested [31].

\section{Statistical analysis of morphometry}

A total of 211 microglia from the CA1/CA2 region were reconstructed, 113 in the infected group and 98 in the control group.

Initially, we investigated the presence of morphological features shared by the microglia observed in our sample, within each experimental group. All quantitative morphometric variables with multimodality indexes (MMI) greater than 0.55 were selected for cluster analysis (Ward's hierarchical clustering method), which included all animals in each group. We estimated the multimodality index (MMI) based on the asymmetry and kurtosis of our sample for each morphometric variable according to the equation: $\mathrm{MMI}=$ $\left[\mathrm{M}^{2}+1\right] /\left[\mathrm{M} 4+3(\mathrm{n}-1)^{2 /}(\mathrm{n}-2)(\mathrm{n}-3)\right]$, where M3 is asymmetry and M4 is kurtosis and $\mathrm{n}$ is the sample size. Kurtosis and asymmetry describe the form of data distribution and allow to distinguish between unimodal, bimodal, or multimodal curves [32,33].

The multimodal index of each variable was estimated based on the measurements of 20 morphometric parameters of the branches of microglia, as follows: 1 . Total length of branches $(\mu \mathrm{m}) ; 2$. Average length of branches $(\mu \mathrm{m}) 3$. Average surface area of branches $\left(\mu \mathrm{m}^{2}\right) ; 4$. Volume of branches $\left(\mu \mathrm{m}^{3}\right) ; 5$. Total number of segments 6 . Segments $/ \mathrm{mm}$; 7 . Tortuosity; 8. Fractal dimensions (k-dim); 9. Base Diameter of Primary Branches ( $\mu \mathrm{m}) ; 10$. Total Trees Surface Area $\left(\mu \mathrm{m}^{2}\right) ; 11$. Planar angle; 12 . Number of trees; 13 . Complexity; 14. Convex-Hull Volume $\left(\mu \mathrm{m}^{3}\right)$; 15. Convex-Hull Surface Area; 16. Convex-Hull Area; 17. Convex-Hull Perimeter; 18. Vertex Va; 19. Vertex Vb; 20. Vertex Vc, (see Table 1 and Figure 4 for more details). Morphological characteristics of microglia with multimodality index greater than 0.55 indicate that their distribution is at least bimodal and can be multimodal [33].

MMI morphometric parameters with normalized scales were selected for the cluster analysis. We used Ward's method with standardized variables, and a tree diagram (dendrogram) to illustrate the classification generated by the cluster analysis.

In order to identify which variables contributed most to the formation of clusters, the data generated by the cluster hierarchical analysis were subjected to analysis of the canonical discriminating function, using the software Statistica 12.0 (Statsoft, Tulsa, OK). The 
purpose of this procedure is to determine whether the groups differ in the mean of a variable and then use that variable to predict group membership. Comparisons between matrices of total variances and covariances were done using multivariate $F$ tests, to determine if there were significant differences between groups (over all variables). In the step-forward discriminant function analysis, the program builds a step-by-step discrimination model. In this model, at each stage, all variables are reviewed and evaluated to determine which variable contributes most to discrimination between groups. We applied this procedure to determine the morphometric variables that provided the best separation between the classes of microglia suggested by the cluster analysis. In addition, we calculated the arithmetic mean and standard deviation for the variables chosen as the best predictors for the microglial groups. Parametric statistical analyzes with t-tests were applied to compare groups of microglia within each experimental group. All CA1/CA2 microglia of the hippocampal formation were measured several times, and dedicated software (Neurolucida explore, MicroBright Field Inc.) was used to process the data obtained. We applied these procedures to our sample of microglia to look for potential morphological classes within each experimental group. For morphometric analysis, we used 20 morphological measures for each of the cells reconstructed in three dimensions. These measures were adapted for the morphometry of the microglia using algorithms designed for morphological measures applied to three-dimensional reconstructions of neurons. The definitions for each variable used are shown in Table 1.

Table 1. Morphological measurements of microscopic three-dimensional reconstructions.

\begin{tabular}{|c|c|}
\hline \multicolumn{2}{|c|}{ Branched Structure Analysis } \\
\hline Segment & $\begin{array}{l}\text { Any portion of microglia branched structure with endings that are either } \\
\text { nodes or terminations with no intermediate nodes. }\end{array}$ \\
\hline Segments/mm & Number of segments/total length of the segments expressed in millimeters. \\
\hline $\mathrm{N}^{\mathrm{o}}$ of Trees & Number of trees in the microglia \\
\hline Total $\mathrm{N}^{\mathrm{o}}$ of Segments & Refer to the total number of segments in the tree. \\
\hline Single Branch Length & Total length of the line segments used to trace the branch of interest. \\
\hline Mean Branch Length $(\mu \mathrm{m})$ & Mean $=[$ Total Length] $][$ Number of branches $]$ \\
\hline Total Branch Length $(\mu \mathrm{m})$ & Total length for all branches in the tree. \\
\hline Tortuosity & $\begin{array}{c}\text { Tortuosity }=[\text { Actual length of the segment]/[Distance between the end- } \\
\text { points of the segment]. The smallest value is } 1 \text {; this represents a straight } \\
\text { segment. Tortuosity allows segments of different lengths to be compared in } \\
\text { terms of the complexity of the paths they take. }\end{array}$ \\
\hline Mean Branch Surface Area $\left(\mu \mathrm{m}^{2}\right)$ & $\begin{array}{l}\text { Computed by modeling each branch as a frustum (truncated right circular } \\
\text { cone) divided by the number of branches. }\end{array}$ \\
\hline Total Tree Surface Area $\left(\mu \mathrm{m}^{2}\right)$ & $\begin{array}{l}\text { 2D surface area of a microglia arbor computed based on the area defined by } \\
\text { the endpoints of all trees. }\end{array}$ \\
\hline Branch Volume $\left(\mu \mathrm{m}^{3}\right)$ & Computed by modeling each piece of each branch as a frustum. \\
\hline Total Branch Volume & Total volume for all branches in the tree. \\
\hline Base Diameter of Primary Branch $(\mu \mathrm{m})$ & Diameter at the start of the $1^{\text {st }}$ segment. \\
\hline Planar Angle & $\begin{array}{l}\text { Computed based on the endpoints of the segments. It refers to the change in } \\
\text { direction of a segment relative to the previous segment. }\end{array}$ \\
\hline $\begin{array}{l}\text { Fractal Dimension } \\
\text { K-Dim }\end{array}$ & $\begin{array}{l}\text { the "k-dim" of the fractal analysis, describes how the structure of interest } \\
\text { fills space. Significant statistical differences in K-dim suggest morphologi- } \\
\text { cal dissimilarities. }\end{array}$ \\
\hline $\begin{array}{l}\text { Convex Hull - Perimeter }(\mu \mathrm{m}) \text {, Area }\left(\mu \mathrm{m}^{2}\right) 2 \mathrm{D} \text {, Sur- } \\
\text { face Area }\left(\mu \mathrm{m}^{2}\right) 3 \mathrm{D} \text { or Volume }\left(\mu \mathrm{m}^{3}\right)\end{array}$ & $\begin{array}{c}\text { Convex hull measures the size of the branching field by interpreting a } \\
\text { branched structure as a solid object controlling a given amount of physical } \\
\text { space. The amount of physical space is defined in terms of convex-hull vol- } \\
\text { ume, surface area, area, and or perimeter. }\end{array}$ \\
\hline Vertex Analysis & $\begin{array}{l}\text { Describes the overall structure of a branched object based on topological } \\
\text { and metrical properties. Root (or origin) point: For neurons, microglia or } \\
\text { astrocytes, the origin is the point at which the structure is attached to the } \\
\text { soma. Main types of vertices: } \mathrm{V}_{\mathrm{d}} \text { (bifurcation) or } \mathrm{V}_{\mathrm{t}} \text { (trifurcation): Nodal } \\
\text { (or branching) points. } \mathrm{V}_{\mathrm{p}} \text { : Terminal (or pendant) vertices. } \mathrm{V}_{\mathrm{a}} \text { : primary verti- } \\
\text { ces connecting } 2 \text { pendant vertices; } \mathrm{V}_{\mathrm{b}} \text { : secondary vertices connecting } 1\end{array}$ \\
\hline
\end{tabular}


pendant vertex $\left(\mathrm{V}_{\mathrm{p}}\right)$ to 1 bifurcation $\left(\mathrm{V}_{\mathrm{d}}\right)$ or 1 trifurcation $\left(\mathrm{V}_{\mathrm{t}}\right) ; \mathrm{V}_{\mathrm{c}}$ : tertiary vertices connecting either 2 bifurcations $\left(V_{d}\right), 2$ trifurcations $\left(V_{t}\right)$, or 1 bifurcation $\left(\mathrm{V}_{\mathrm{d}}\right)$ and 1 trifurcation $\left(\mathrm{V}_{\mathrm{t}}\right)$. In the present report, we measured the number of vertices $\mathrm{Va}, \mathrm{Vb}$ and $\mathrm{Vc}$. branch length/Number of primary branches]

\section{Results}

Overall, the results showed that the reactive microglia of infected animals exhibited more complex trees, greater number of thicker branches that cover a larger volume of tissue than the microglia of control animals.

\section{Microglial metamorphosis: from surveillance to reactivity to virus encephalitis}

Figure 1 simultaneously illustrates the cluster analysis dendrogram (Figure 1A), the three-dimensional reconstructions of microglia corresponding to each cluster (Figure 1B), and the discriminant function analysis (Figure 1C). The microglial representative cells of CA1/CA2 in Figure 1B illustrate 3 morphotypes for each group. For the choice of the "average cell", that illustrates each morphotype the distance matrix was used to obtain the sum of the distances of each cell relative to all others. The matrices were constructed with the combination of all cells of a given group taken pairwise, followed by the weighted calculation of a scalar Euclidean distance between cells using all morphometric variables.

To show the morphological kaleidoscopic of each cluster, we identify the cell with the smallest (top), the median (middle) and the largest (bottom) sum of the distances. Using this algorithm, it became apparent the greater morphological variation of microglia in the CA1/CA2 of infected animals as compared with controls. Thus, from the analysis of Figure 1, nine contrasting morphotypes ( 3 of each cluster) are exhibited, revealing diverse morphological phenotypes of the microglia. In addition, it emerges that the multivariate quantitative analysis when grouping similar cells based on their morphometry may hide part of the morphological diversity if the average cell that best represent each group is indicated only by the least sum of distance between cells. Note that the microglia representative of the infected animals (blue and green) shows a greater number of thicker branches covering larger amount of tissue and connected to larger cell bodies than microglia of the control group (orange). Figure 1C shows a graphic representation of the results of the canonical discriminant function analysis performed with groups indicated by the cluster analysis, based on the morphometric variables that most contributed to the cluster formation. Note that the empty circles corresponding to each experimental group preserve the colors originally used in the hierarchical cluster analysis, each of which occupies distinct regions of the Euclidean space with minimal overlap between groups 1 and 2 and 1 and 3. No overlap is observed between groups 2 and 3. The separation between the centroids (indicated by the black asterisk) is greater between the control group (group 3) and group 2 of the infected animals. The latter contains microglia with the greatest expansion of its trees. Note microglia of the control group less disperse, suggesting greater morphological similarity among them. The separation between the centroids (indicated by the black asterisk) is greater between the control group (group 3) and group 2 of the infected animals. The latter contains microglia with the greatest expansion of its trees. Function 1 of the discriminant analysis corresponded to $91.8 \%$ of the variance and included the surface of the convex hull, the total volume of the branches and the morphological complexity as morphometric variables that contributed most to the variance (see supplementary material SM1). 
A

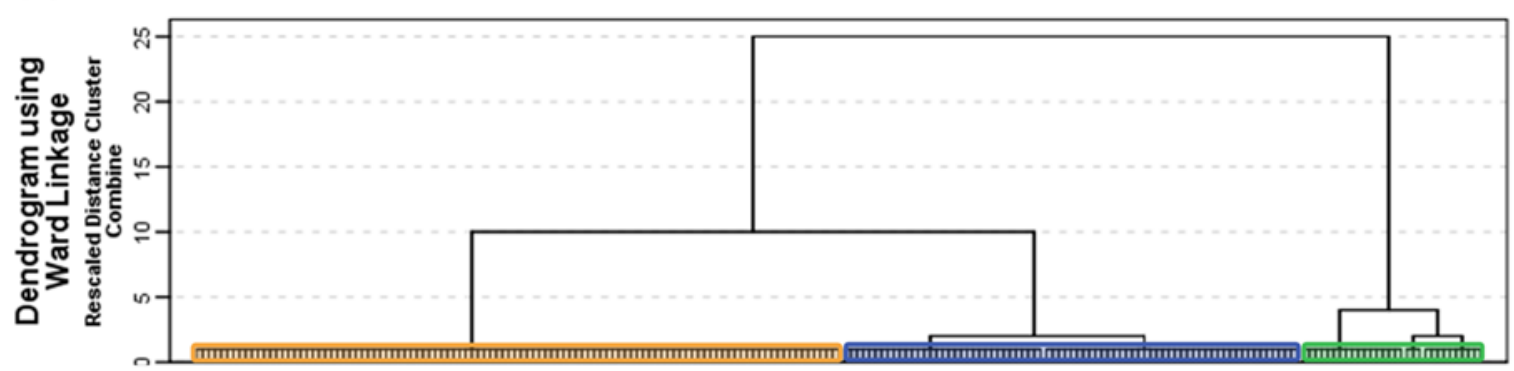

B

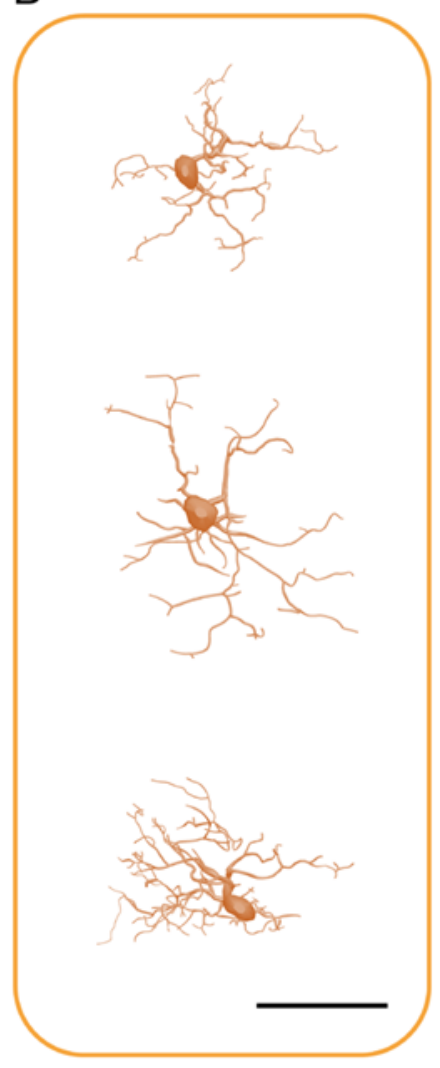

C

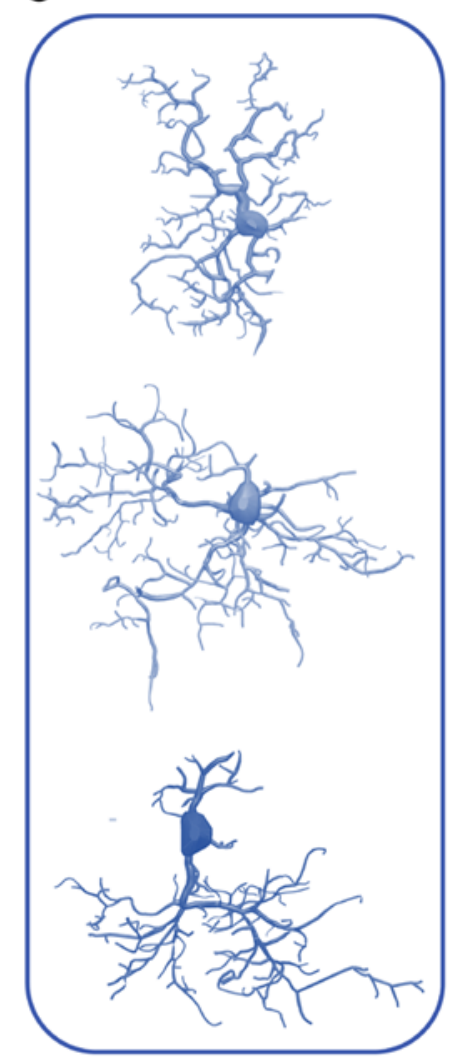

D

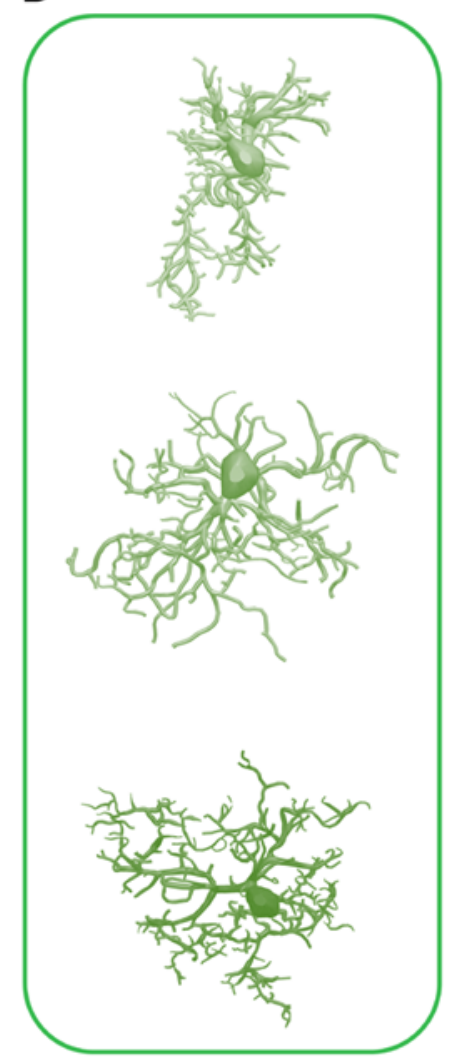

$E$

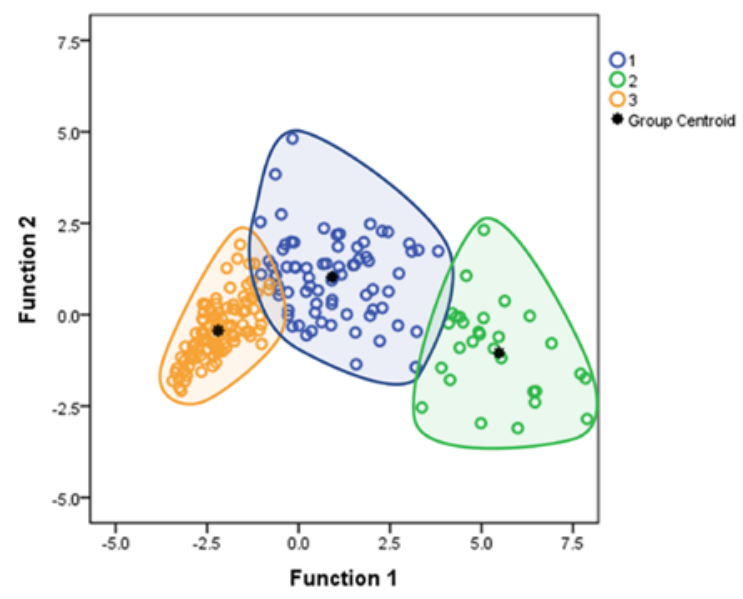

Canonical Discriminant Functions

Figure 1. A: Hierarchical cluster analysis for morphological classification of microglia from CA1/CA2 of control and Piry virus infected animals at 8 days post-infection. Note the occurrence of three main clusters, two of them bringing together microglia of infected animals (Blue and Green) and another for microglia of the control group (Orange). The morphometric variables used in the analysis were those with a multimodality index above 0.55 with at least bimodal distribution. B, C 
and D: Representative cells of each cluster based on the greatest, the median and the shortest distances between pairs, after multiple comparisons. The cells that best represent each group were based on the values of the short (upper row), the median (intermediate) and the greater (bottom row) sum of distances. E: Canonical discriminating function analysis illustrating the distribution of microglia in the Euclidean space as a function of the clusters identified by the hierarchical cluster analysis. Note that the distribution of microglia in the Euclidean space of control animals (orange) is much more compact than the distribution of microglia of infected animals (blue and green) suggesting greater homogeneity of morphology in that group. The variables that most contributed to the formation of clusters were the surface of the convex hull, the total volume of the branches and the complexity. For detailed information on the statistical analysis see supplementary material SM1.

Figure 2 shows the mean values with the corresponding standard deviations and standard errors for the surface of the convex hull surface and for the total branch volume of each experimental group. The convex hull data measures the size of the tissue volume covered by the microglial trees. It interprets a branching structure as a solid 3D object controlling a certain amount of physical space. The amount of physical space is defined in terms of the volume of tissue covered by the tree of a single microglia. The convex hull surface illustrated in Figure 3 represents the sum of the areas of the faces of the corresponding irregular convex polyhedron defined by microglial branches.

From the analysis of the Figure 2 it became apparent that the Piry virus encephalitis induced significant expansion of microglial trees and the total volume of its branches.

A

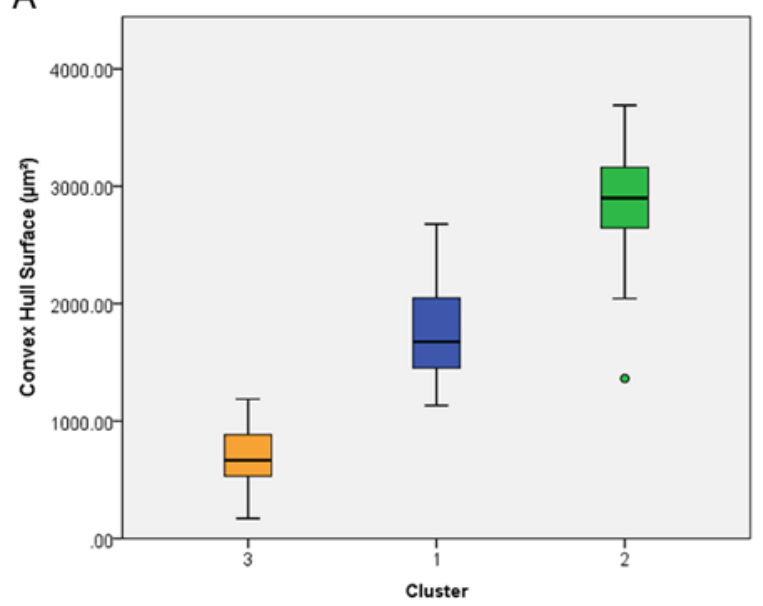

B

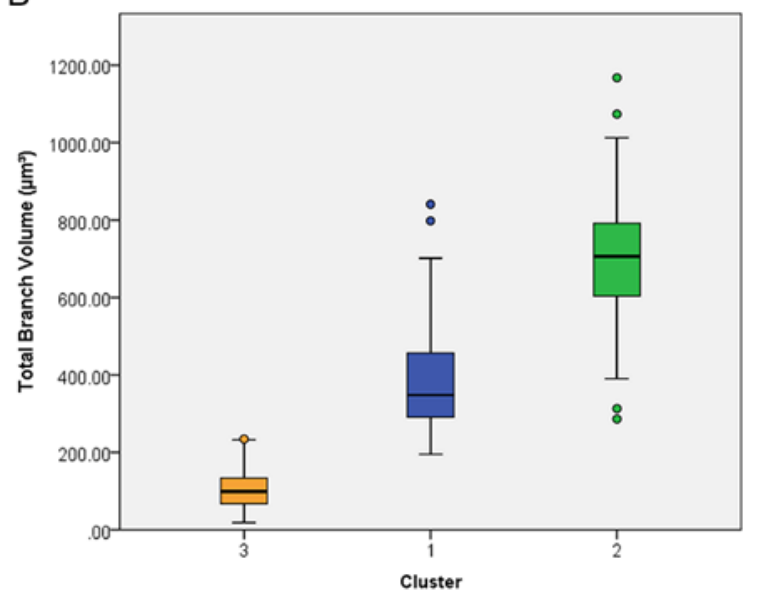

Figure 2. Graphical representation of the mean values and corresponding errors and standard deviations for the surface of the convex hull and for the total volume of branches of infected animals in clusters 1 (blue), and 2 (green), and control animals - cluster 3 (orange). Note that when compared to the microglia of the control animals, the mean value of the convex hull surface area of the microglia of the infected animals is 3 to 6 folds greater.

Figure 3 are graphic representations of the mean values with the corresponding standard deviations and errors of the morphological complexity and of the branch volume of each experimental group. In general, the lowest mean values for these morphometric variables correspond to the microglia of the control animals (orange boxes). The highest values (in green) and the intermediate values (in blue) came from microglia of infected animals. 
A

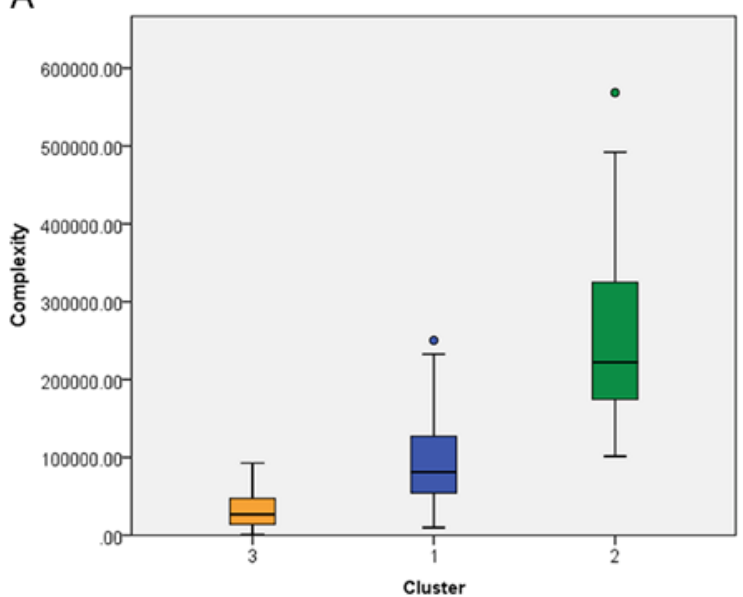

B

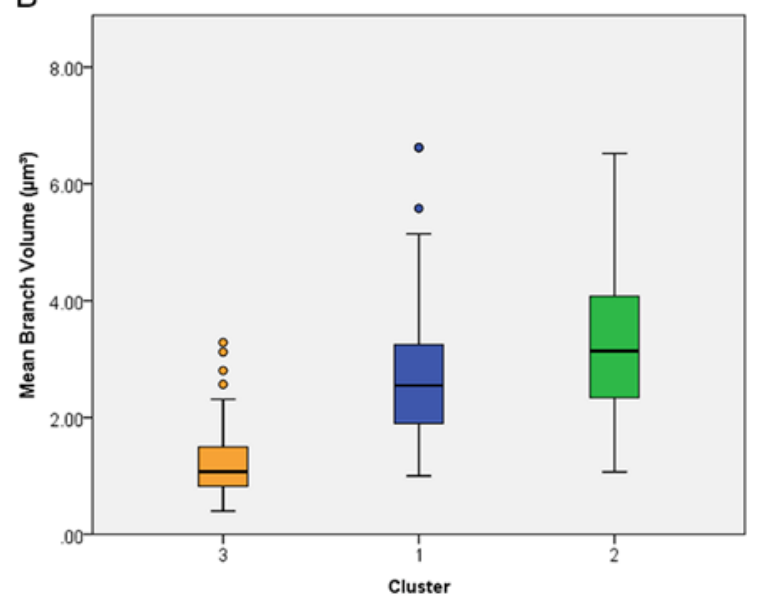

Figure 3. Graphical representation of the mean values and corresponding errors and standard deviations for the complexity and the average volume of the microglia branches of clusters 1 (blue) and 2 (green) of the infected animals and for the microglia of the control animals (cluster 3 - orange). Note that the microglia of the control animals are less complex and exhibit thinner branches than the microglia of the infected animals.

The definitions of morphological complexity (Figure 3) are based on the following equation:

Complexity $=[$ Sum of the terminal orders + Number of terminals $] \times[$ Total branch length/Number of primary branches].

Note that, from the equation for morphological complexity, it can be roughly inferred that this morphometric indicator analyzes in an integrated manner a series of parameters of the microglial tree that, together with the volume of the convex hull, suggested significant dissimilarity between control and infected microglial features.

Figure 4 illustrates in a three-dimensional Cartesian representation the values of the 3 variables that most contributed to the formation of clusters including the values for the microglia from control (orange) and infected (green and blue) animals. In the $\mathrm{Y}$ axis, the values for the convex hull surface area are represented, in the $X$ axis the total volume of the branches and in the $\mathrm{Z}$ axis the values for the morphological complexity.

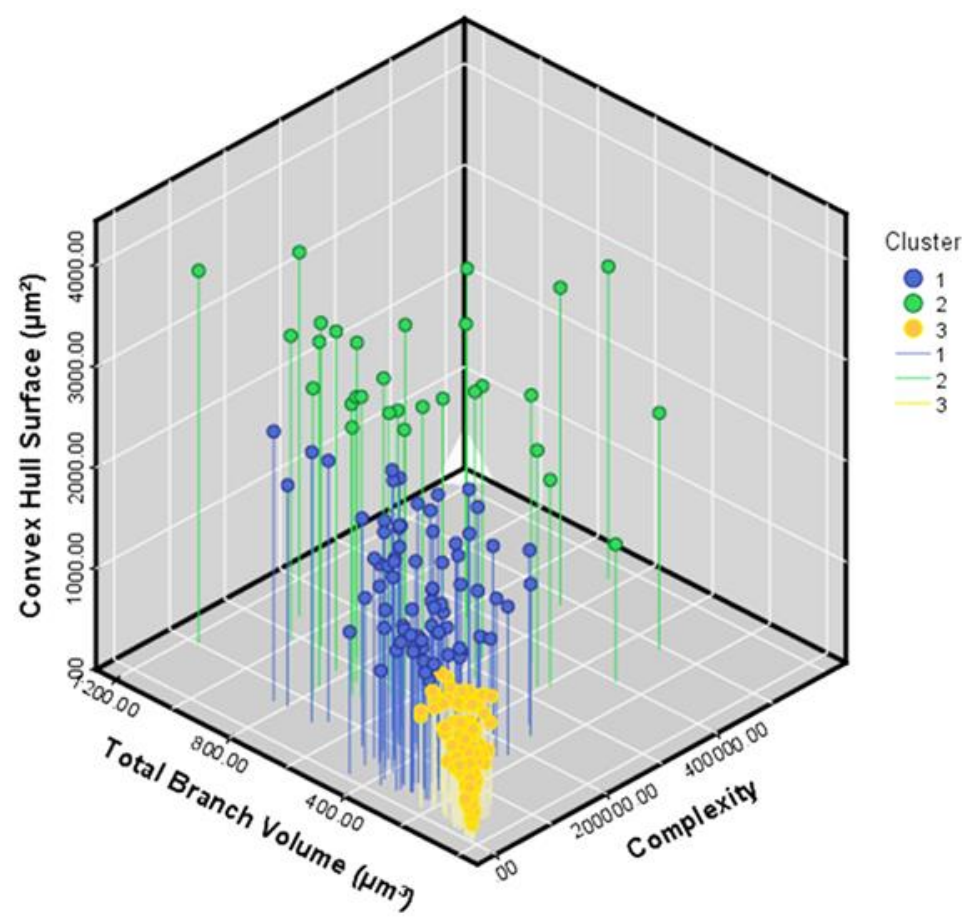


Figure 4. Figure 4. Three-dimensional graphic representation of the mean values of morphometric variables that most contributed to the cluster formation. The values of the surface area of the convex hull are indicated on the $Y$ axis, the values of the total volume of the branches are indicated on the $\mathrm{X}$ axis and the morphological complexity on the $\mathrm{Z}$ axis. Note that the lower mean values on the three morphometric variables correspond to the orange filled circles of the control animals and the greatest ones correspond to group 2 of the infected animals (filled green circles on top of green lines).

Table 2 exhibits the values of the descriptive statistics for the morphometric variables indicated by the analysis of the discriminant function, accounting for $91.8 \%$ of the variance.

Table 2. Descriptive statistical results for morphometric variables that contributed most to the formation of clusters. The data for the groups are shown as 1, 2 and 3 on each line. Groups 1 and 2 correspond to the microglia of the infected animals and group 3 to the microglia of the control animals. Note that the lowest mean values for each variable are found in the group of control animals (group 3) and the highest values are found in animals in group 2 of infected animals.

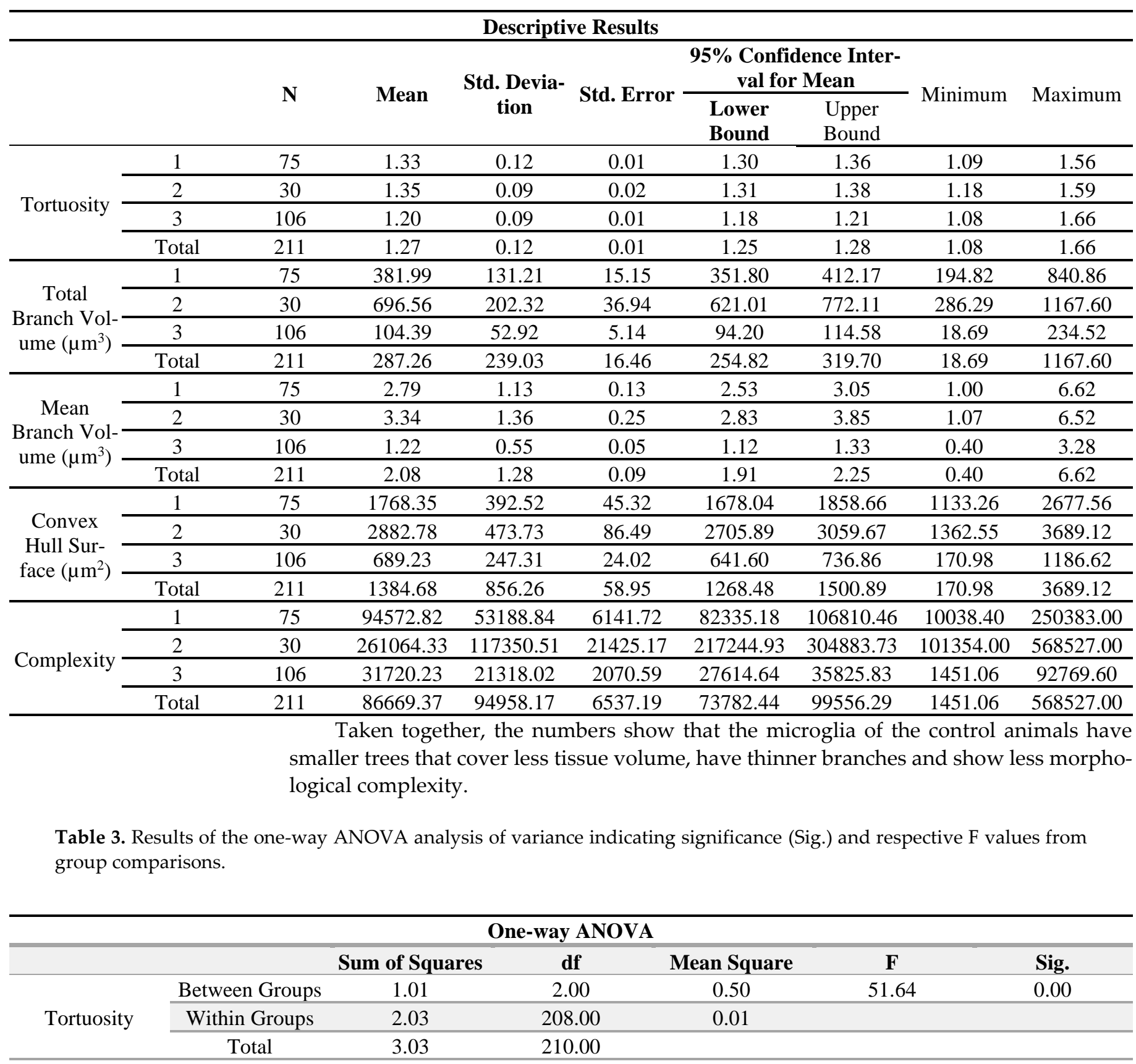




\begin{tabular}{|c|c|c|c|c|c|c|}
\hline \multirow{3}{*}{$\begin{array}{l}\text { Total Branch } \\
\text { Volume }\left(\mu \mathrm{m}^{3}\right)\end{array}$} & Between Groups & 9243466.58 & 2.00 & 4621733.29 & 348.92 & 0.00 \\
\hline & Within Groups & 2755100.53 & 208.00 & 13245.68 & & \\
\hline & Total & 11998567.12 & 210.00 & & & \\
\hline \multirow{3}{*}{$\begin{array}{l}\text { Mean Branch } \\
\text { Volume }\left(\mu \mathrm{m}^{3}\right)\end{array}$} & Between Groups & 163.21 & 2.00 & 81.61 & 94.20 & 0.00 \\
\hline & Within Groups & 180.20 & 208.00 & 0.87 & & \\
\hline & Total & 343.41 & 210.00 & & & \\
\hline \multirow{3}{*}{$\begin{array}{l}\text { Convex Hull Sur- } \\
\text { face }\left(\mu \mathrm{m}^{2}\right)\end{array}$} & Between Groups & 129635754.77 & 2.00 & 64817877.38 & 554.10 & 0.00 \\
\hline & Within Groups & 24331445.08 & 208.00 & 116978.10 & & \\
\hline & Total & 153967199.85 & 210.00 & & & \\
\hline \multirow{3}{*}{ Complexity } & Between Groups & $\begin{array}{c}1237150125189.3 \\
1\end{array}$ & 2.00 & 618575062594.66 & 196.00 & 0.00 \\
\hline & Within Groups & 656431092622.02 & 208.00 & 3155918714.53 & & \\
\hline & Total & $\begin{array}{c}1893581217811.3 \\
4\end{array}$ & 210.00 & & & \\
\hline
\end{tabular}

In contrast, the reactive microglia have a more complex tree and thicker branches that cover a greater volume of tissue. The analysis of variance shown in Table 3 confirms that these morphological differences were highly significant.

The multiple comparisons for the Tukey HSD and Bonferroni tests for the same morphometric variables have their results shown in Table 4. Except for the tortuosity that does not distinguish between the groups of infected animals, all other morphometric variables are significantly different distinguishing the infected groups controls and distinguishing groups 1 and 2 of infected animals.

Table 4. Multiple comparisons of the values of the morphometric variables of the CA1/CA2 microglia of infected animals (groups 1 and 2) and controls (group 3). Except for tortuosity that shows no significant difference in the comparison of the infected groups with each other, all other morphometric variables show significant differences in all comparisons. $\left(^{*}\right)$ indicates significant statistical difference.

\section{Multiple Comparisons}

\begin{tabular}{|c|c|c|c|c|c|c|c|c|}
\hline \multirow{2}{*}{$\begin{array}{c}\text { Dependent } \\
\text { Variable }\end{array}$} & \multirow{2}{*}{\multicolumn{3}{|c|}{ Testes e Comparações entre Grupos }} & \multirow[b]{2}{*}{$\begin{array}{l}\text { Mean Differ- } \\
\text { ence }(\mathbf{I}-\mathbf{J})\end{array}$} & \multirow[b]{2}{*}{ Std. Error } & \multirow[b]{2}{*}{ Sig. } & \multicolumn{2}{|c|}{ 95\% Confidence Interval } \\
\hline & & & & & & & $\begin{array}{l}\text { Lower } \\
\text { Bound }\end{array}$ & $\begin{array}{l}\text { Upper } \\
\text { Bound }\end{array}$ \\
\hline \multirow{12}{*}{ Tortuosity } & \multirow{6}{*}{ Tukey HSD } & \multirow{2}{*}{$1 v s$} & 2 & -0.017 & 0.021 & 0.710 & -0.067 & 0.034 \\
\hline & & & 3 & $0.13291^{*}$ & 0.015 & 0.000 & 0.098 & 0.168 \\
\hline & & \multirow{2}{*}{2} & 1 & 0.017 & 0.021 & 0.710 & -0.034 & 0.067 \\
\hline & & & 3 & $0.14976^{*}$ & 0.020 & 0.000 & 0.102 & 0.198 \\
\hline & & \multirow{2}{*}{3} & 1 & $-0.13291^{*}$ & 0.015 & 0.000 & -0.168 & -0.098 \\
\hline & & & 2 & $-0.14976^{*}$ & 0.020 & 0.000 & -0.198 & -0.102 \\
\hline & \multirow{6}{*}{ Bonferroni } & \multirow{2}{*}{$1 v s$} & 2 & -0.017 & 0.021 & 1.000 & -0.068 & 0.035 \\
\hline & & & 3 & $0.13291^{*}$ & 0.015 & 0.000 & 0.097 & 0.169 \\
\hline & & \multirow{2}{*}{2} & 1 & 0.017 & 0.021 & 1.000 & -0.035 & 0.068 \\
\hline & & & 3 & $0.14976^{*}$ & 0.020 & 0.000 & 0.100 & 0.199 \\
\hline & & \multirow{2}{*}{3} & 1 & $-0.13291^{*}$ & 0.015 & 0.000 & -0.169 & -0.097 \\
\hline & & & 2 & $-0.14976^{*}$ & 0.020 & 0.000 & -0.199 & -0.100 \\
\hline \multirow{8}{*}{$\begin{array}{l}\text { Total Branch } \\
\text { Volume } \\
\left(\mu \mathrm{m}^{3}\right)\end{array}$} & \multirow{6}{*}{ Tukey HSD } & \multirow{2}{*}{$1 v s$} & 2 & $-314.57115^{*}$ & 24.862 & 0.000 & -373.261 & -255.881 \\
\hline & & & 3 & $277.59531^{*}$ & 17.366 & 0.000 & 236.602 & 318.589 \\
\hline & & \multirow{2}{*}{2} & 1 & $314.57115^{*}$ & 24.862 & 0.000 & 255.881 & 373.261 \\
\hline & & & 3 & $592.16647^{*}$ & 23.801 & 0.000 & 535.982 & 648.351 \\
\hline & & \multirow{2}{*}{3} & 1 & $-277.59531^{*}$ & 17.366 & 0.000 & -318.589 & -236.602 \\
\hline & & & 2 & $-592.16647^{*}$ & 23.801 & 0.000 & -648.351 & -535.982 \\
\hline & \multirow{2}{*}{ Bonferroni } & \multirow{2}{*}{$1 v s$} & 2 & $-314.57115^{*}$ & 24.862 & 0.000 & -374.576 & -254.566 \\
\hline & & & 3 & $277.59531^{*}$ & 17.366 & 0.000 & 235.683 & 319.507 \\
\hline
\end{tabular}




\begin{tabular}{|c|c|c|c|c|c|c|c|c|}
\hline & & \multirow{2}{*}{2} & 1 & $314.57115^{*}$ & 24.862 & 0.000 & 254.566 & 374.576 \\
\hline & & & 3 & $592.16647^{*}$ & 23.801 & 0.000 & 534.723 & 649.610 \\
\hline & & \multirow{2}{*}{3} & 1 & $-277.59531^{*}$ & 17.366 & 0.000 & -319.507 & -235.683 \\
\hline & & & 2 & $-592.16647^{*}$ & 23.801 & 0.000 & -649.610 & -534.723 \\
\hline \multirow{12}{*}{$\begin{array}{c}\text { Mean Branch } \\
\text { Volume } \\
\left(\mu \mathrm{m}^{3}\right)\end{array}$} & \multirow{6}{*}{ Tukey HSD } & \multirow{2}{*}{$1 v s$} & 2 & $-0.55013^{*}$ & 0.201 & 0.018 & -1.025 & -0.075 \\
\hline & & & 3 & $1.56653^{*}$ & 0.140 & 0.000 & 1.235 & 1.898 \\
\hline & & 2 & 1 & $0.55013^{*}$ & 0.201 & 0.018 & 0.075 & 1.025 \\
\hline & & 2 & 3 & $2.11666^{*}$ & 0.192 & 0.000 & 1.662 & 2.571 \\
\hline & & & 1 & $-1.56653^{*}$ & 0.140 & 0.000 & -1.898 & -1.235 \\
\hline & & 3 & 2 & $-2.11666^{*}$ & 0.192 & 0.000 & -2.571 & -1.662 \\
\hline & & $1 u_{c}$ & 2 & $-0.55013^{*}$ & 0.201 & 0.020 & -1.035 & -0.065 \\
\hline & & IVS & 3 & $1.56653^{*}$ & 0.140 & 0.000 & 1.228 & 1.905 \\
\hline & Ronferroni & 2 & 1 & $0.55013^{*}$ & 0.201 & 0.020 & 0.065 & 1.035 \\
\hline & Bonrerron1 & 2 & 3 & $2.11666^{*}$ & 0.192 & 0.000 & 1.652 & 2.581 \\
\hline & & 3 & 1 & $-1.56653^{*}$ & 0.140 & 0.000 & -1.905 & -1.228 \\
\hline & & 3 & 2 & $-2.11666^{*}$ & 0.192 & 0.000 & -2.581 & -1.652 \\
\hline & & $1 v_{\mathrm{C}}$ & 2 & $-1114.43247^{*}$ & 73.885 & 0.000 & -1288.846 & -940.019 \\
\hline & & IVs & 3 & $1079.11491^{*}$ & 51.607 & 0.000 & 957.291 & 1200.939 \\
\hline & Tukey HSD & 2 & 1 & $1114.43247^{*}$ & 73.885 & 0.000 & 940.019 & 1288.846 \\
\hline & I UKЕУ ПDD & 2 & 3 & $2193.54738^{*}$ & 70.731 & 0.000 & 2026.579 & 2360.515 \\
\hline & & 3 & 1 & $-1079.11491^{*}$ & 51.607 & 0.000 & -1200.939 & -957.291 \\
\hline Convex Hull & & 3 & 2 & $-2193.54738^{*}$ & 70.731 & 0.000 & -2360.515 & -2026.579 \\
\hline Surface $\left(\mu \mathrm{m}^{2}\right)$ & & مب & 2 & $-1114.43247^{*}$ & 73.885 & 0.000 & -1292.754 & -936.111 \\
\hline & & IVs & 3 & $1079.11491^{*}$ & 51.607 & 0.000 & 954.562 & 1203.668 \\
\hline & Bonferroni & 2 & 1 & $1114.43247^{*}$ & 73.885 & 0.000 & 936.111 & 1292.754 \\
\hline & Bonterron1 & 2 & 3 & $2193.54738^{*}$ & 70.731 & 0.000 & 2022.839 & 2364.256 \\
\hline & & 3 & 1 & $-1079.11491^{*}$ & 51.607 & 0.000 & -1203.668 & -954.562 \\
\hline & & 3 & 2 & $-2193.54738^{*}$ & 70.731 & 0.000 & -2364.256 & -2022.839 \\
\hline & & $1 v s$ & 2 & $\begin{array}{c}- \\
166491.5146 \\
7^{*} \\
\end{array}$ & 12135.741 & 0.000 & -195139.323 & -137843.707 \\
\hline & & & 3 & $62852.58386^{*}$ & 8476.540 & 0.000 & 42842.739 & 82862.429 \\
\hline & & & 1 & $\begin{array}{c}166491.5146 \\
7^{*}\end{array}$ & 12135.741 & 0.000 & 137843.707 & 195139.323 \\
\hline & Tukey HSD & 2 & 3 & $\begin{array}{c}229344.0985 \\
2^{*} \\
\end{array}$ & 11617.664 & 0.000 & 201919.271 & 256768.926 \\
\hline Complexity & & & 1 & $\begin{array}{c}- \\
62852.58386^{*} \\
\end{array}$ & 8476.540 & 0.000 & -82862.429 & -42842.739 \\
\hline & & 3 & & - & & & & \\
\hline & & & 2 & $\begin{array}{c}229344.0985 \\
2^{*} \\
\end{array}$ & 11617.664 & 0.000 & -256768.926 & -201919.271 \\
\hline & & $1 v s$ & 2 & $\begin{array}{c}- \\
166491.5146 \\
7^{*}\end{array}$ & 12135.741 & 0.000 & -195781.101 & -137201.929 \\
\hline & Bonferroni & & 3 & $62852.58386^{*}$ & 8476.540 & 0.000 & 42394.471 & 83310.697 \\
\hline & & 2 & 1 & $\begin{array}{c}166491.5146 \\
7^{*}\end{array}$ & 12135.741 & 0.000 & 137201.929 & 195781.101 \\
\hline
\end{tabular}




\begin{tabular}{lcccccc} 
& 3 & $\begin{array}{c}229344.0985 \\
2^{*}\end{array}$ & 11617.664 & 0.000 & 201304.891 & 257383.306 \\
\hline \multirow{3}{*}{3} & 1 & $\begin{array}{c}- \\
62852.58386^{*}\end{array}$ & 8476.540 & 0.000 & -83310.697 & -42394.471 \\
\cline { 2 - 7 } & 2 & $\begin{array}{c}229344.0985 \\
2^{*}\end{array}$ & 11617.664 & 0.000 & -257383.306 & -201304.891 \\
\hline
\end{tabular}

*. The mean difference is significant at the 0.05 level.

\section{Discussion}

In the present study, we expanded to CA1/CA2 previous efforts dedicated to CA3 where the Piry arbovirus was used as a model to induce experimental encephalitis in adult females of the Swiss albino mouse seeking to investigate the influence of age and the environment on the microglial morphology in correlation with disease progression [34]. From the anatomical series of brain sections from that work, and using the stereological sampling approach, we reconstructed microglia in three dimensions at the $8^{\text {th }}$-day postinfection. With hierarchical cluster analysis followed by linear discriminant function analysis, we classified the microglia of CA1/CA2 from control and infected mice and compared their morphology and morphometry We found three large morphological clusters, two of which in infected animals and one in control animals. To identify the cells that best represent the morphological kaleidoscopic of each cluster, we estimate the smallest (top), the median (middle) and the largest (bottom) sum of the distances. The matrices were constructed using all morphometric variables with the combination of all cells in a given group, followed by the weighted calculation of a scalar Euclidean distance between the cells. This approach revealed greater morphological variation in the CA1/CA2 microglia of infected and control animals. Indeed, we found nine contrasting morphotypes (3 for each suggested cluster), revealing morphological aspects of the microglia that would otherwise be encapsulated in the hermetic standard procedures of multivariate analysis.

\section{Piry Virus Neuroinvasion and Microglial Response}

Although most viral infections are concentrated in peripheral tissues (non-neurotropic viruses), many viral species reach the central nervous system where can alter homeostasis, and induce neurological dysfunction associated with life-threatening inflammatory diseases [5,35-37].

The Piry arbovirus was previously chosen as a model for experimental studies due to the low level of biosafety required to work with it, to belong to the South American group of RNA-viruses, be found in Brazil [38,39], produce experimental encephalitis in neonatal and adult mice [40-43], with the advantage that in humans is associated with mild febrile human disease [44,45].

Neurotropic viruses can use the olfactory system as a route for the invasion of the mammalian central nervous system, which is the pathway used by the herpes simplex virus 1 [46], mouse hepatitis virus [47], pseudorabdovirus [48], Venezuelan equine encephalitis virus [49] and the CVS variety of the rabies virus [50]. After the infection in the cerebral parenchyma, after neuroinvasion through the olfactory nerves Piry virus antigens were concentrated in limbic areas, including olfactory bulb, septum and hippocampus [23].

During virus infections a sustained increase in extracellular ATP induced by neuronal damage is sensed by microglia through the purinergic receptor P2Y12 followed by its activation and recruitment towards virus infected neurons, to exert phagocytic activity in minutes to hours [51] and the number of P2Y12 receptors on the surface of microglia increases over twofold in response to viral infections [4]. ATP is a strong chemotactic signal for young microglia, mediating its rapid migration to the injury site [52]. Thus, purinergic signaling is essential for modulation of microglial movement in the normal and pathological brain [28,53]. 
If we assume that the form and function are intertwined, and yet morphology precedes function both in developmental [54] and mature brain circuits [55], we can raise significant issues from the morphometric analysis of microglia either from homeostatic or altered conditions [56-58].

In the present work, we demonstrated with help of cluster analysis, that in control animals kept in standard laboratory cages, the microglia of infected animals respond with significant changes by diversifying their morphology in the face of encephalitis induced by Piry arbovirus. This included increasing its complexity, the volume of tissue covered by its branches, and increasing the number of branches and thickness of them. Complexity, as defined previously (Pillai et al. 2012), uses the following equation: Complexity = (Sum of the terminal orders + Number of terminals) * (Total branch length/Number of primary branches). When applied to microglial morphology, the increasing of this this index was found to be associated with hyper-ramified and longer processes even in the absence of inflammation or neurodegeneration in the prefrontal cortex of rats subjected to chronic stress $[59,60]$. Chronic stress significantly increases the branching complexity of microglia and enhances ramification maintaining the area occupied by the cell. Notably, mice subjected to chronic stress express TNF $\alpha$, albeit at relatively low levels, and exhibit activation and pro-ramifying microglia effects in the prefrontal cortex (Couch et al. 2013). Likewise, a significant increase in TNF $\alpha$ immunostaining was demonstrated in association with an intense microglial response with thickening of the branches and an increase in their number morphological complexity in a dengue viral single infection model [61] or in exacerbated inflammatory response induced by heterologous antibody-enhancement dengue disease [62,63].

Some studies using different experimental models have previously documented an increased expression of $\beta$-integrin expression in microglia response in the altered CNS, with an increase in microglial morphological diversity with hypertrophy and increase in the number and thickness of their branches, [64,65].

In viral infections, the comparison of changes in the transcriptome of astrocytes and microglia after innate immune stimulation by viral infections, allows the identification of glial activation markers [66]. The morphological analysis of the microglia shows that the signaling of the type I neuron receptor (IFN) has a stronger impact on the activation of cells of myeloid origin (microglia) than on astrocytes. In addition to interferon- $\beta$ (IFN- $\beta$ ) induction, CNS infection by the olfactory pathway results in the recruitment of myeloid cells, such as microglia [67], and peripheral immune cells, such as dendritic cells [68], T cells and monocytes in the CNS [23,69], and that cross-talk between neurons, astrocytes and microglia is critical for complete microglia activation and for protection against lethal encephalitis [70].

\section{Reactive microglial morphology}

With multiple processes that expand and retract continuously, guided by its sensome [71], microglia represent the most important cellular component of the innate immune response in the central nervous system [10,72,73].

Morphological studies in fixed tissue such as this, in general allow an instant view of the microglial morphology of a given region associated with different experimental conditions and windows. In the present report we classified three-dimensionally reconstructed microglia from fixed tissue of infected and control animals, using the hierarchical cluster analysis and the linear discriminant function analysis of multimodal morphometric features. We found three main clusters, two of which in infected animals and one in control animals.

Microglia and macrophages have been described classically as capable of generating two main types of response: M1, which has a pro-inflammatory profile and can be mediated by TNF-alpha and IFN-gamma, and M2, an alternative anti-inflammatory pathway, which acts in the resolution of inflammation and tissue repair and that can be mediated by IL-4 [74]. However, more recently, much has been discussed about the existence of 
several other reactive microglia phenotypes in addition to those recognized as M1 and M2, doubting the existence of this binary classification [75]. With the advent of new technologies, it has become more evident that the previous binary classification of microglia in profiles M1 and M2 is an oversimplification of the multitude of physiological roles of microglia [76].

Indeed, when we compared the morphological parameters found in the present report with those previously described as M1 and M2 [57,77-79], it becomes apparent that the microglia morphology of infected animals and controls do not easily adjust to this binary classification. The detailed analysis of the microglia dispersed in the Euclidean space using the distance matrix based on all morphometric variables (Figure 1) and using minimal, median and greater sum of distances matrix, revealed nine different morphological patterns.

In this work, the morphometric measurements of the microglia of infected Piry virus infected and control groups, showed that the reactive microglia have more complex trees and thicker branches that cover a larger volume of tissue than the microglia of the control animals. Using unbiased stereological approach to select microglia for reconstruction and hierarchical cluster analysis we identified the representative cells of each cluster using the largest, the median and the smallest sum of the scalar distances using all the other cells for comparisons. With this algorithm, a greater morphological variation in the CA1/CA2 microglia of the infected and control animals became apparent, with nine distinct morphotypes (three from control and six from infected animals). Thus, the most reliable representation of the microglia dispersion in the Euclidean space, reflecting more broadly the spectrum of morphotypes of the control and infected groups, suggests that the way in which multivariate statistical results are generally represented may encapsulate the complete pictorial representation, hiding the morphological kaleidoscope of surveillant and reactive microglia. As form precedes function in nature, our findings are a good starting point for future research with integrative approaches to microglia form and function.

Supplementary 1: Multivariate analysis illustrating the results of hierarchical cluster analysis (A) and discriminant function analysis (B). Detailed statistical data of discriminant function analysis are available in Tables C - F.

Funding: This work was supported by the following institutional grants: Fundação de Amparo à Pesquisa do Pará - FADESP/Pró-Reitoria de Pesquisa e Pós-Graduação da Universidade Federal do Pará - PROPESP Edital 2019-PIAPA; Coordenação de Aperfeiçoamento de Pessoal de Nível Superior - CAPES - Pró-Amazônia, Grant No. 3311/2013; Brazilian Research Council - CNPq Grant No: 307749/2004-5 and 471077/2007-0 for CWPD, Fundação Amazônia de Amparo a Estudos e Pesquisas do Pará - FAPESPA, ICAAF No 039/2017.

Availability of Data: The dataset(s) supporting the conclusions of this article are included within the article.

Data Sharing: Authors declare that under request, all qualitative and quantitative data including excel spreadsheet will be shared.

Additional Information: The author(s) declare that they have no competing interests.

Authors Contribution: All authors made substantial contributions to the design of the work, acquisition, analysis and interpretation of the data; they either wrote the work or substantially revised it. They also approved the submitted version and agreed to be personally responsible for their own contributions, ensuring that issues related to the accuracy or completeness of any part of the work, even those in which they were not personally involved, were properly investigated or documented.

\section{References}

1. George, B.P.; Schneider, E.B.; Venkatesan, A. Encephalitis hospitalization rates and inpatient mortality in the United States, 2000-2010. PLoS ONE 2014, 9, e104169, doi:10.1371/journal.pone.0104169.

2. Barzon, L. Ongoing and emerging arbovirus threats in Europe. J Clin Virol 2018, 107, 38-47, doi:10.1016/j.jcv.2018.08.007.

3. Go, Y.Y.; Balasuriya, U.B.; Lee, C.K. Zoonotic encephalitides caused by arboviruses: Transmission and epidemiology of alphaviruses and flaviviruses. Clin Exp Vaccine Res 2014, 3, 58-77, doi:10.7774/cevr.2014.3.1.58. 
4. Chen, Z.; Zhong, D.; Li, G. The role of microglia in viral encephalitis: A review. J Neuroinflammation 2019, 16, 76, doi:10.1186/s12974-019-1443-2.

5. Klein, R.S.; Garber, C.; Funk, K.E.; Salimi, H.; Soung, A.; Kanmogne, M.; Manivasagam, S.; Agner, S.; Cain, M. Neuroinflammation During RNA Viral Infections. Annu Rev Immunol 2019, 37, 73-95, doi:10.1146/annurev-immunol-042718-041417.

6. Clé, M.; Eldin, P.; Briant, L.; Lannuzel, A.; Simonin, Y.; Van de Perre, P.; Cabié, A.; Salinas, S. Neurocognitive impacts of arbovirus infections. J Neuroinflammation 2020, 17, 233, doi:10.1186/s12974-020-01904-3.

7. Dos Santos, S.E.; Medeiros, M.; Porfirio, J.; Tavares, W.; Pessôa, L.; Grinberg, L.; Leite, R.E.P.; Ferretti-Rebustini, R.E.L.; Suemoto, C.K.; Filho, W.J.; et al. Similar Microglial Cell Densities across Brain Structures and Mammalian Species: Implications for Brain Tissue Function. J Neurosci 2020, 40, 4622-4643, doi:10.1523/JNEUROSCI.2339-19.2020.

8. Masuda, T.; Sankowski, R.; Staszewski, O.; Prinz, M. Microglia Heterogeneity in the Single-Cell Era. Cell Rep 2020, 30, 12711281, doi:10.1016/j.celrep.2020.01.010.

9. Geirsdottir, L.; David, E.; Keren-Shaul, H.; Weiner, A.; Bohlen, S.C.; Neuber, J.; Balic, A.; Giladi, A.; Sheban, F.; Dutertre, C.A.; et al. Cross-Species Single-Cell Analysis Reveals Divergence of the Primate Microglia Program. Cell 2019, 179, 1609-1622.e1616, doi:10.1016/j.cell.2019.11.010.

10. Perry, V.H. Microglia. Microbiol Spectr 2016, 4, doi:10.1128/microbiolspec.MCHD-0003-2015.

11. Nimmerjahn, A.; Kirchhoff, F.; Helmchen, F. Resting microglial cells are highly dynamic surveillants of brain parenchyma in vivo. Science 2005, 308, 1314-1318, doi:1110647 [pii]10.1126/science.1110647.

12. Wake, H.; Moorhouse, A.J.; Jinno, S.; Kohsaka, S.; Nabekura, J. Resting microglia directly monitor the functional state of synapses in vivo and determine the fate of ischemic terminals. J Neurosci 2009, 29, 3974-3980, doi:10.1523/JNEUROSCI.4363-08.2009.

13. Weinhard, L.; di Bartolomei, G.; Bolasco, G.; Machado, P.; Schieber, N.L.; Neniskyte, U.; Exiga, M.; Vadisiute, A.; Raggioli, A.; Schertel, A.; et al. Microglia remodel synapses by presynaptic trogocytosis and spine head filopodia induction. Nat Commun 2018, 9, 1228, doi:10.1038/s41467-018-03566-5.

14. Ikegami, A.; Haruwaka, K.; Wake, H. Microglia: Lifelong modulator of neural circuits. Neuropathology 2019, 39, 173-180, doi:10.1111/neup.12560.

15. Illes, P.; Rubini, P.; Ulrich, H.; Zhao, Y.; Tang, Y. Regulation of Microglial Functions by Purinergic Mechanisms in the Healthy and Diseased CNS. Cells 2020, 9, doi:10.3390/cells9051108.

16. Madry, C.; Kyrargyri, V.; Arancibia-Cárcamo, I.L.; Jolivet, R.; Kohsaka, S.; Bryan, R.M.; Attwell, D. Microglial Ramification, Surveillance, and Interleukin-1 $\beta$ Release Are Regulated by the Two-Pore Domain K. Neuron 2018, 97, 299-312.e296, doi:10.1016/j.neuron.2017.12.002.

17. Bernier, L.P.; Bohlen, C.J.; York, E.M.; Choi, H.B.; Kamyabi, A.; Dissing-Olesen, L.; Hefendehl, J.K.; Collins, H.Y.; Stevens, B.; Barres, B.A.; et al. Nanoscale Surveillance of the Brain by Microglia via cAMP-Regulated Filopodia. Cell Rep 2019, 27, 28952908.e2894, doi:10.1016/j.celrep.2019.05.010.

18. Hanamsagar, R.; Alter, M.D.; Block, C.S.; Sullivan, H.; Bolton, J.L.; Bilbo, S.D. Generation of a microglial developmental index in mice and in humans reveals a sex difference in maturation and immune reactivity. Glia 2017, 65, 1504-1520, doi:10.1002/glia.23176.

19. Holtman, I.R.; Skola, D.; Glass, C.K. Transcriptional control of microglia phenotypes in health and disease. J Clin Invest 2017, 127, 3220-3229, doi:10.1172/JCI90604.

20. Minten, C.; Terry, R.; Deffrasnes, C.; King, N.J.; Campbell, I.L. IFN regulatory factor 8 is a key constitutive determinant of the morphological and molecular properties of microglia in the CNS. PLoS ONE 2012, 7, e49851, doi:10.1371/journal.pone.0049851.

21. Harris, K.M. Structural LTP: From synaptogenesis to regulated synapse enlargement and clustering. Curr Opin Neurobiol 2020, 63, 189-197, doi:10.1016/j.conb.2020.04.009.

22. Davis, E.J.; Foster, T.D.; Thomas, W.E. Cellular forms and functions of brain microglia. Brain Res Bull 1994, $34,73-78$.

23. de Sousa, A.A.; Reis, R.; Bento-Torres, J.; Trevia, N.; Lins, N.A.D.; Passos, A.; Santos, Z.; Diniz, J.A.P.; Vasconcelos, P.F.D.; Cunningham, C.; et al. Influence of Enriched Environment on Viral Encephalitis Outcomes: Behavioral and Neuropathological Changes in Albino Swiss Mice. PLoS ONE 2011, 6, doi:10.1371/journal.pone.0015597.

24. Xiao, S.Y.; Guzman, H.; Zhang, H.; Travassos da Rosa, A.P.; Tesh, R.B. West Nile virus infection in the golden hamster (Mesocricetus auratus): A model for West Nile encephalitis. Emerg Infect Dis 2001, 7, 714-721, doi:10.3201/eid0704.010420.

25. Reed , H.; Muench, H. A simple method of estimating fifty per cent endpoints. American Journal of Epidemiology 1938, 27, 493497.

26. Hawk, C.; Leary, S.; Morris, T. Formulary for Laboratory Animals, 3rd edition ed.; Blackwell Publishing: Iowa, USA, 2005.

27. Ohsawa, K.; Imai, Y.; Sasaki, Y.; Kohsaka, S. Microglia/macrophage-specific protein Iba1 binds to fimbrin and enhances its actinbundling activity. J Neurochem 2004, 88, 844-856, doi:10.1046/j.1471-4159.2003.02213.x.

28. Ohsawa, K.; Kohsaka, S. Dynamic motility of microglia: Purinergic modulation of microglial movement in the normal and pathological brain. Glia 2011, doi:10.1002/glia.21238.

29. Paxinos, G.; Franklin, K. The mouse brain in stereotaxic coordinates.; Academic Press: London, UK, 2001.

30. West, M.J. Design-based stereological methods for counting neurons. Prog Brain Res 2002, 135, 43-51.

31. Carlo, C.N.; Stevens, C.F. Analysis of differential shrinkage in frozen brain sections and its implications for the use of guard zones in stereology. J Comp Neurol 2011, 519, 2803-2810, doi:10.1002/cne.22652.

32. Kolb, H.; Fernandez, E.; Schouten, J.; Ahnelt, P.; Linberg, K.A.; Fisher, S.K. Are there three types of horizontal cell in the human retina? J Comp Neurol 1994, 343, 370-386, doi:10.1002/cne.903430304.

33. Schweitzer, L.; Renehan, W.E. The use of cluster analysis for cell typing. Brain Res Brain Res Protoc 1997, 1, 100-108. 
34. de Sousa, A.A.; Dos Reis, R.R.; de Lima, C.M.; de Oliveira, M.A.; Fernandes, T.N.; Gomes, G.F.; Diniz, D.G.; Magalhães, N.M.; Diniz, C.G.; Sosthenes, M.C.; et al. Three-dimensional morphometric analysis of microglial changes in a mouse model of virus encephalitis: Age and environmental influences. Eur J Neurosci 2015, doi:10.1111/ejn.12951.

35. McGavern, D.B.; Kang, S.S. Illuminating viral infections in the nervous system. Nat Rev Immunol 2011, 11, 318-329, doi:10.1038/nri2971.

36. Klein, R.S.; Garber, C.; Howard, N. Infectious immunity in the central nervous system and brain function. Nat Immunol 2017, 18, 132-141, doi:10.1038/ni.3656.

37. Payus, A.O.; Liew Sat Lin, C.; Mohd Noh, M.; Jeffree, M.S.; Ali, R.A. SARS-CoV-2 infection of the nervous system: A review of the literature on neurological involvement in novel coronavirus disease-(COVID-19). Bosn J Basic Med Sci 2020, 20, 283-292, doi:10.17305/bjbms.2020.4860.

38. Weaver, S.C. Evolutionary influences in arboviral disease. Curr Top Microbiol Immunol 2006, 299, $285-314$.

39. Marriott, A.C. Complete genome sequences of Chandipura and Isfahan vesiculoviruses. Arch Virol 2005, 150, 671-680, doi:10.1007/s00705-004-0452-2.

40. Gomes-Leal, W.; Martins, L.C.; Diniz, J.A.P.; Dos Santos, Z.A.; Borges, J.A.; Macedo, C.A.C.; Medeiros, A.C.; De Paula, L.S.; Guimaraes, J.S.; Freire, M.A.M.; et al. Neurotropism and neuropathological effects of selected rhabdoviruses on intranasallyinfected newborn mice. Acta Tropica 2006, 97, 126-139, doi:10.1016/j.actatropica.2005.09.006.

41. Wilks, C.R.; House, J.A. Susceptibility of various animals to the vesiculovirus Piry. J Hyg (Lond) 1984, 93, 147-155.

42. da Cruz, E.R. [Ultrastructural lesions of the brain in albino mice experimentally inoculated with Piry virus (BeAn 24232)]. Rev Inst Med Trop Sao Paulo 1981, 23, 194-203.

43. de Sousa, A.A.; Reis, R.; Bento-Torres, J.; Trevia, N.; Lins, N.A.; Passos, A.; Santos, Z.; Diniz, J.A.; Vasconcelos, P.F.; Cunningham, C.; et al. Influence of enriched environment on viral encephalitis outcomes: Behavioral and neuropathological changes in albino Swiss mice. PLOS ONE 2011, 6, e15597.

44. Berge, T. International catalogue of arboviruses, 2nd ed.; Dept of Health, Education andWelfare, Centers for Disease Control: Atlanta, Georgia, 1975.

45. Vasconcelos, P.F.; Da Rosa, J.F.; Da Rosa, A.P.; Degallier, N.; Pinheiro, F.P.; Sa Filho, G.C. Epidemiology of encephalitis caused by arbovirus in the Brazilian Amazonia. Rev. Inst. Med.Trop. Sao Paulo 1991, 33, 465-476.

46. Esiri, M.M.; Tomlinson, A.H. Herpes simplex encephalitis. Immunohistological demonstration of spread of virus via olfactory and trigeminal pathways after infection of facial skin in mice. J Neurol Sci 1984, 64, 213-217.

47. Barnett, E.M.; Perlman, S. The olfactory nerve and not the trigeminal nerve is the major site of CNS entry for mouse hepatitis virus, strain JHM. Virology 1993, 194, 185-191, doi:S0042-6822(83)71248-1 [pii]10.1006/viro.1993.1248.

48. Babic, N.; Mettenleiter, T.C.; Ugolini, G.; Flamand, A.; Coulon, P. Propagation of pseudorabies virus in the nervous system of the mouse after intranasal inoculation. Virology 1994, 204, 616-625.

49. Charles, P.C.; Walters, E.; Margolis, F.; Johnston, R.E. Mechanism of neuroinvasion of Venezuelan equine encephalitis virus in the mouse. Virology 1995, 208, 662-671, doi:S0042-6822(85)71197-X [pii]10.1006/viro.1995.1197.

50. Lafay, F.; Coulon, P.; Astic, L.; Saucier, D.; Riche, D.; Holley, A.; Flamand, A. Spread of the CVS strain of rabies virus and of the avirulent mutant AvO1 along the olfactory pathways of the mouse after intranasal inoculation. Virology 1991, 183, 320-330.

51. Fekete, R.; Cserép, C.; Lénárt, N.; Tóth, K.; Orsolits, B.; Martinecz, B.; Méhes, E.; Szabó, B.; Németh, V.; Gönci, B.; et al. Microglia control the spread of neurotropic virus infection via P2Y12 signalling and recruit monocytes through P2Y12-independent mechanisms. Acta Neuropathol 2018, 136, 461-482, doi:10.1007/s00401-018-1885-0.

52. Davalos, D.; Grutzendler, J.; Yang, G.; Kim, J.V.; Zuo, Y.; Jung, S.; Littman, D.R.; Dustin, M.L.; Gan, W.-B. ATP mediates rapid microglial response to local brain injury in vivo. Nature neuroscience 2005, 8, 752-758.

53. Hassan-Abdi, R.; Brenet, A.; Bennis, M.; Yanicostas, C.; Soussi-Yanicostas, N. Neurons Expressing Pathological Tau Protein Trigger Dramatic Changes in Microglial Morphology and Dynamics. Front Neurosci 2019, 13, 1199, doi:10.3389/fnins.2019.01199.

54. Menassa, D.A.; Gomez-Nicola, D. Microglial Dynamics During Human Brain Development. Front Immunol 2018, 9, 1014, doi:10.3389/fimmu.2018.01014.

55. Wierzba-Bobrowicz, T.; Kosno-Kruszewska, E.; Gwiazda, E.; Lechowicz, W. The comparison of microglia maturation in different structures of the human nervous system. Folia Neuropathol 1998, 36, 152-160.

56. Karperien, A.; Ahammer, H.; Jelinek, H.F. Quantitating the subtleties of microglial morphology with fractal analysis. Frontiers in cellular neuroscience 2013, 7.

57. Fernández-Arjona, M.D.M.; Grondona, J.M.; Granados-Durán, P.; Fernández-Llebrez, P.; López-Ávalos, M.D. Microglia Morphological Categorization in a Rat Model of Neuroinflammation by Hierarchical Cluster and Principal Components Analysis. Front Cell Neurosci 2017, 11, 235, doi:10.3389/fncel.2017.00235.

58. Fernández-Arjona, M.D.M.; Grondona, J.M.; Fernández-Llebrez, P.; López-Ávalos, M.D. Microglial Morphometric Parameters Correlate With the Expression Level of IL-1 $\beta$, and Allow Identifying Different Activated Morphotypes. Front Cell Neurosci 2019, 13, 472, doi:10.3389/fncel.2019.00472.

59. Hinwood, M.; Morandini, J.; Day, T.A.; Walker, F.R. Evidence that microglia mediate the neurobiological effects of chronic psychological stress on the medial prefrontal cortex. Cereb Cortex 2012, 22, 1442-1454, doi:10.1093/cercor/bhr229.

60. Hinwood, M.; Tynan, R.J.; Charnley, J.L.; Beynon, S.B.; Day, T.A.; Walker, F.R. Chronic stress induced remodeling of the prefrontal cortex: Structural re-organization of microglia and the inhibitory effect of minocycline. Cereb Cortex 2013, 23, 1784-1797, doi:10.1093/cercor/bhs151. 
61. Gomes, G.F.; Peixoto, R.D.D.F.; Maciel, B.G.; Santos, K.F.D.; Bayma, L.R.; Feitoza Neto, P.A.; Fernandes, T.N.; de Abreu, C.C.; Casseb, S.M.M.; de Lima, C.M.; et al. Differential Microglial Morphological Response, TNF $\alpha$, and Viral Load in Sedentary-like and Active Murine Models After Systemic Non-neurotropic Dengue Virus Infection. J Histochem Cytochem 2019, 67, 419-439, doi:10.1369/0022155419835218.

62. Diniz, D.G.; Silva, G.O.; Naves, T.B.; Fernandes, T.N.; Araujo, S.C.; Diniz, J.A.P.; de Farias, L.H.S.; Sosthenes, M.C.K.; Diniz, C.G.; Anthony, D.C.; et al. Hierarchical Cluster Analysis of Three-Dimensional Reconstructions of Unbiased Sampled Microglia Shows not Continuous Morphological Changes from Stage 1 to 2 after Multiple Dengue Infections in Callithrix penicillata. Frontiers in Neuroanatomy 2016, 10, doi:10.3389/fnana.2016.00023.

63. Vasconcelos, B.C.B.; Vieira, J.A.; Silva, G.O.; Fernandes, T.N.; Rocha, L.C.; Viana, A.P.; Serique, C.D.S.; Santos, C.; Bringel, R.A.R.; Teixeira, F.; et al. Antibody-enhanced dengue disease generates a marked CNS inflammatory response in the black-tufted marmoset Callithrix penicillata. Neuropathology 2016, 36, 3-16, doi:10.1111/neup.12229.

64. Ayoub, A.E.; Salm, A.K. Increased morphological diversity of microglia in the activated hypothalamic supraoptic nucleus. $J$ Neurosci 2003, 23, 7759-7766.

65. Kloss, C.U.; Bohatschek, M.; Kreutzberg, G.W.; Raivich, G. Effect of lipopolysaccharide on the morphology and integrin immunoreactivity of ramified microglia in the mouse brain and in cell culture. Exp Neurol 2001, 168, 32-46, doi:10.1006/exnr.2000.7575.

66. Madeddu, S.; Woods, T.A.; Mukherjee, P.; Sturdevant, D.; Butchi, N.B.; Peterson, K.E. Identification of Glial Activation Markers by Comparison of Transcriptome Changes between Astrocytes and Microglia following Innate Immune Stimulation. PLoS ONE 2015, 10, e0127336, doi:10.1371/journal.pone.0127336.

67. Getts, D.R.; Terry, R.L.; Getts, M.T.; Müller, M.; Rana, S.; Shrestha, B.; Radford, J.; Van Rooijen, N.; Campbell, I.L.; King, N.J. Ly6c+ "inflammatory monocytes" are microglial precursors recruited in a pathogenic manner in West Nile virus encephalitis. $J$ Exp Med 2008, 205, 2319-2337, doi:10.1084/jem.20080421.

68. D'Agostino, P.M.; Kwak, C.; Vecchiarelli, H.A.; Toth, J.G.; Miller, J.M.; Masheeb, Z.; McEwen, B.S.; Bulloch, K. Viral-induced encephalitis initiates distinct and functional CD103+ CD11b+ brain dendritic cell populations within the olfactory bulb. Proc Natl Acad Sci U S A 2012, 109, 6175-6180, doi:10.1073/pnas.1203941109.

69. Steel, C.D.; Hahto, S.M.; Ciavarra, R.P. Peripheral dendritic cells are essential for both the innate and adaptive antiviral immune responses in the central nervous system. Virology 2009, 387, 117-126, doi:S0042-6822(09)00072-5 [pii]10.1016/j.virol.2009.01.032.

70. Chhatbar, C.; Detje, C.N.; Grabski, E.; Borst, K.; Spanier, J.; Ghita, L.; Elliott, D.A.; Jordão, M.J.C.; Mueller, N.; Sutton, J.; et al. Type I Interferon Receptor Signaling of Neurons and Astrocytes Regulates Microglia Activation during Viral Encephalitis. Cell Rep 2018, 25, 118-129.e114, doi:10.1016/j.celrep.2018.09.003.

71. Hickman, S.E.; El Khoury, J. Analysis of the Microglial Sensome. Methods Mol Biol 2019, 2034, 305-323, doi:10.1007/978-1-49399658-2_23.

72. Garaschuk, O.; Verkhratsky, A. Physiology of Microglia. Methods Mol Biol 2019, 2034, 27-40, doi:10.1007/978-1-4939-9658-2_3.

73. Sierra, A.; Paolicelli, R.C.; Kettenmann, H. Cien Años de Microglía: Milestones in a Century of Microglial Research. Trends Neurosci 2019, 42, 778-792, doi:10.1016/j.tins.2019.09.004.

74. Hanisch, U.K.; Kettenmann, H. Microglia: Active sensor and versatile effector cells in the normal and pathologic brain. Nat Neurosci 2007, 10, 1387-1394, doi:nn1997 [pii]10.1038/nn1997.

75. Ransohoff, R.M. A polarizing question: Do M1 and M2 microglia exist? Nat Neurosci 2016, 19, 987-991, doi:10.1038/nn.4338.

76. Dubbelaar, M.L.; Kracht, L.; Eggen, B.J.L.; Boddeke, E.W.G.M. The Kaleidoscope of Microglial Phenotypes. Front Immunol 2018, 9, 1753, doi:10.3389/fimmu.2018.01753.

77. Orihuela, R.; McPherson, C.A.; Harry, G.J. Microglial M1/M2 polarization and metabolic states. Br J Pharmacol 2016, 173, 649665, doi:10.1111/bph.13139.

78. Salvi, V.; Sozio, F.; Sozzani, S.; Del Prete, A. Role of Atypical Chemokine Receptors in Microglial Activation and Polarization. Front Aging Neurosci 2017, 9, 148, doi:10.3389/fnagi.2017.00148.

79. Yuan, Y.; Wu, C.; Ling, E.A. Heterogeneity of Microglia Phenotypes: Developmental, Functional and Some Therapeutic Considerations. Curr Pharm Des 2019, 25, 2375-2393, doi:10.2174/1381612825666190722114248. 